\title{
"A comparison of public and private schools in Spain using robust nonparametric frontier methods"
}

\author{
José Manuel Cordero Ferrera ${ }^{\mathrm{a}^{*}}$ \\ Diego Prior ${ }^{\mathrm{b}}$ \\ Rosa Simancas Rodríguez ${ }^{\mathrm{a}}$
}

${ }^{\text {a }}$ Universidad de Extremadura, Spain

${ }^{b}$ Universitat Autònoma de Barcelona, Spain

\begin{abstract}
This paper uses an innovative approach to evaluate educational performance of Spanish students in PISA 2009. Our purpose is to decompose their overall inefficiency between different components with a special focus on studying the differences between public and state subsidized private schools. We use a technique inspired by the non-parametric Free Disposal Hull $(\mathrm{FDH})$ and the application of robust order- $m$ models, which allow us to mitigate the influence of outliers and the curse of dimensionality. Subsequently, we adopt a metafrontier framework to assess each student relative to the own group best practice frontier (students in the same school) and to different frontiers constructed from the best practices of different types of schools. The results show that state-subsidised private schools outperform public schools, although the differences between them are significantly reduced once we control for the type of students enrolled in both type of centres.
\end{abstract}

Key words: Education, Efficiency, Multilevel Modelling, Free Disposal Hull.

* Corresponding author at: Departamento de Economía, Universidad de Extremadura,

Av. Elvas s/n, 06071 Badajoz, Spain

E-mail address: jmcordero@ unex.es; Tlf. +34 924289300, Fax: +34924272509 


\section{INTRODUCTION}

Since the pioneer study of Coleman et al. (1982), the debate about the performance of private and public schools has become one of the main topics of research in a wide range of educational contexts (Rouse and Barrow 2009). In general terms, it is widely assumed that private schools are likely to perform better than public schools because market competition forces them to achieve a more efficient use of resources (Friedman and Friedman 1981; Chubb and Moe 1990; Hoxby 2003). However, empirical studies comparing both, public and private schools, need to control for differences in the personal and socio-economic background of students as well as the potential self-selection bias that can arise because more informed and motivated parents are more likely to apply to better schools (Mayston 2003; Tamm 2008; Burgess and Briggs 2010).

The conclusions reached in the vast literature devoted to this issue are mixed. Some studies find that private schools do better, even after controlling for the aforementioned factors (Jiménez et al. 1991; Toma 1996; Altonji et al. 2005; Dronkers and Robert 2008; Annand et al. 2009; Dronkers and Avram 2010; Kim 2011), although the differences are reduced or disappear when those variables are taken into account (Williams and Carpenter 1991; Goldhaber 1996; Sander 1996; McEwan and Carnoy 2000; McEwan 2001; Vandenberghe and Robin 2004; Hsieh and Urquiola 2006; Chudgar and Quin 2012) or even public schools can outperform private ones (Bifulco and Ladd 2006; Newhouse and Beegle 2006).

Most of the previous works use an approach based on the estimation of educational production functions, following the approach developed by Hanushek et al. (1986, 1986, 2003). However, this approach does not explore the presence of potential inefficient behaviors, since it is based on average measures (Godstein 1997). In this paper we are interested in analyzing differences between public and private schools using frontier techniques, which are based on the construction of a boundary composed of the most efficient units that serves as a benchmark for comparison. Among these models, the nonparametric approach has been the most frequently option in the educational context, due to its ability to handle multiple intermediate outputs and its flexibility, which makes it particularly suitable in an area where the production technology is difficult to define (Mancebón and Bandrés 1999).

This approach has been mainly applied to estimate efficiency measures using data at school or school district level (Bessent and Bessent 1980; Bessent et al. 1982; Thanassoulis and Dunstan 1994; Mancebon and Molinero 2000; Grosskopf and Moutray 2001; Banker et al. 2004). In our case we are interested in working with student level data, since this possibility implies some significant advantages for interpreting the results obtained in the analysis and disentangling the 
effect of multiple factors affecting the performance of students (Summers and Wolf, 1977; Hanushek, 1996; Waldo, 2007). Furthermore, the measurement of efficiency at student level allows considering separately student's own socioeconomic background and their schoolmates' one (the so-called peer-group effect), two inputs which cannot be simultaneously included with aggregated data (Santín 2006).

This paper contributes to the above literature by applying a new method to estimate the differences in efficiency between public and private schools. In this sense, it must be noted that the educational system in Spain represents a relevant case study, since two types of schools compete for public funds: public and state-subsidized private schools ${ }^{1}$. The former are managed by public authorities while the latter are owned and managed directly or indirectly by a private non-government organization (mainly Catholic entities) ${ }^{2}$. This scheme aims at allowing parents to freely design their preferred school and, indirectly, stimulating competition among schools to improve their performance. In this context, the comparison between their levels of efficiency becomes extremely attractive.

The recent literature provides some empirical studies focused on this comparison using Spanish data with different methodological approaches, although the findings are still inconclusive. Hence, Mancebon and Muñiz (2008) do not find significant differences after using an extension of Silva Portela and Thanassoulis (2001) proposal. The same conclusion is reached by Calero and Escardibul (2007) using multilevel analysis and Perelman and Santín (2011) using parametric stochastic distance functions. Mancebon et al. (2012) obtain even better results for public schools combining the use of multilevel analysis with the same extension of DEA. In contrast, Crespo-Cebada et al. (2014) conclude that, after applying a propensity score matching technique to correct the potential bias, students attending state-subsidized private schools perform significantly better than students from public schools.

In this work we combine the application of two recently developed nonparametric methods to estimate the efficiency of both types of schools. Firstly, we use the order- $m$ partial frontiers approach (Cazals et al. 2002) in order to avoid some of the main drawbacks of the nonparametric methods, such as the high impact of atypical observations or the bias that can arise when the evaluated units (students) are grouped into groups (schools) of different size

\footnotetext{
${ }^{1}$ There are also private government-independent schools, controlled by non-government organizations, which are mainly funded through student fees. However, in this paper, we focus only on the publicly financed schools.

${ }^{2}$ According to the regulation, these institutions can only benefit from government subsidies if they fulfill some requirements, such as providing education free of charge, maintaining a certain rate of pupil-teacher ratio, teaching the official curriculum and not allowing any type of discrimination among students in their admission processes. See Mancebon and Muñiz (2008) or Mancebon et al. (2012) for details.
} 
(Zhang and Bartels 1998). This approach consists of using only part of the sample ( $m$ observations) to determine efficiency scores, thus it mitigates the impact of outliers and potential errors in data and assures the same size for the reference set, avoiding the curse of dimensionality that systematically pursues the traditional nonparametric estimations (Daraio and Simar 2007). Secondly, in order to assess the performance of both types of schools we adopt the metafrontier framework, developed by Battese and Rao (2002), Battese et al. (2004) and O’Donnell et al. (2008). This method allows us to assess each student relative to their own group (meaning, students attending the same type of schools) and, secondly, to the overall metafrontier, constructed from the best practices of both types of schools.

De Witte et al. (2010) were pioneers in using those methods to assess the performance of a sample of British secondary schools, although they only evaluate public centres. Cherchye et al. (2010) also used a robust nonparametric approach to assess educational efficiency of Flemish pupils attending public and private primary schools, although their comparison between different types of schools is based on stochastic dominance criteria. De Witte and Kortelainen (2013) use the partial order- $m$ approach to estimate the efficiency of Dutch pupils in PISA, but their focus is placed on the identification of exogenous variables affecting the performance of students and not on comparing public and private schools. Finally, Thieme et al. (2013) represents the only previous study in which both approaches employed in this paper are combined to assess the performance of students in primary education in Chile, although they do not consider the managerial decomposition between public and private schools. Therefore, this paper represents the first combined application of both methods using data from secondary schools. In particular, we analyse the performance of Spanish students in PISA 2009, which provides a wide volume of data regarding multiple factors that can affect the performance at student and school level.

The rest of the paper is organized as follows. Section 2 presents the methods used to estimate students' efficiency and separate the school effect. Section 3 describes the main characteristics of the dataset and the criteria followed to select the variables included in the analysis. Section 4 discusses the main results. Finally, section 5 provides concluding remarks.

\section{METHODOLOGY}

\subsection{The deterministic model}

The definition of the production technology that a student uses to acquire knowledge is a very difficult task. The only thing that we know is that pupils transform a set of inputs $x\left(x \in \mathfrak{R}_{+}^{p}\right)$ such as their own capabilities or their parental background into heterogeneous outputs 
$y\left(y \in \mathfrak{R}_{+}^{q}\right)$, usually represented by their results in standardized test scores. This can be represented by equation (1):

$$
\psi=\left\{(x, y) \in \mathfrak{R}_{+}^{p+q} \mid x \text { can produce } y\right\}
$$

In order to estimate the relative efficiency of each student, we need to constitute a frontier that represents the best performing students. This boundary set is characterized by the following expression:

$$
\begin{aligned}
& \theta \psi=\{(x, y) \in \psi \mid(\theta x, y) \notin \psi, \forall 0<\theta<1,(x, \lambda y) \notin \psi, \forall \lambda>1\} \\
& \psi=\{(x, y) \in \psi \mid(\theta x, y) \notin \psi, \forall 0<\theta<1,(x, \lambda y) \notin \psi, \forall \lambda>1\}
\end{aligned}
$$

A procedure to measure the relative inefficiency scores is represented by nonparametric techniques, represented by Data Envelopment Analysis -DEA- (Charnes et al. 1978) and Free Disposal Hull -FDH- (Deprins et al. 1984). Both DEA and FDH estimate the technology set $\psi$ by the smallest set $\hat{\psi}$ that envelops the observed data, but FDH differs from DEA in its removal of the convexity assumption. In practical terms, this implies that each unit (student) is compared only to other existing unit (student), and that it cannot be evaluated against any convex combinations of efficient units. Although DEA is more popular among researchers in the field of education, in our study we opt for using FDH because it has higher flexibility, it has comparatively superior asymptotic properties (Park et al. 2000; Simar and Wilson 2000) and it ensures that all reference units are real ${ }^{3}$. The output oriented efficiency score $\left(\hat{\theta}_{F D H}\right)$ of an observation can be obtained by solving the mixed integer linear programming problem in equation (6):

$$
\hat{\theta}_{F D H}=\max \left\{\lambda \mid \lambda y \leq \sum_{i=1}^{N} \gamma_{i} y_{i} ; x \geq \sum_{i=1}^{N} \gamma_{i} x_{i} ; \sum_{i=1}^{N} \gamma_{i}=1 ; \gamma_{i} \in\{0,1\} ; i=1, \ldots ., n\right\}
$$

where $\hat{\theta}_{F D H}=1$ denotes an efficient pupil, while $\hat{\theta}_{F D H}>1$ implies that the pupil is inefficient. However, this nonparametric approach, as well as DEA, presents some significant shortcomings that should be born in mind when using nonparametric methods to assess efficiency at student level: (1) statistical inference is not possible due to its deterministic nature; (2) it is very sensitive to the presence of outliers and measurement errors in data; (3) it experiences

\footnotetext{
${ }^{3}$ Oliveira and Santos (2005) also use this approach to assess efficiency in the educational context.
} 
dimensionality problems due to their slow convergence rates. In the next sections, we explain some approaches that can be used in order to overcome these limitations.

\subsection{The robust approach}

The first attempts to improve the robustness of nonparametric methods were the works of Kneipp et al. (1998) and Simar and Wilson (2000). Subsequently, Cazals et al. (2002) introduced the robust order- $m$ estimation. This approach is related to the FDH estimator, but instead of constructing a full frontier, it creates a partial frontier that envelops only $m(\geq 1)$ observations randomly drawn from the sample. This procedure is repeated $B$ times resulting in

multiple measures $\left(\hat{\theta}_{m i}^{1}, \ldots, \hat{\theta}_{m i}^{B}\right)$ from which the final order- $m$ efficiency measure is computed as the simple mean $\left(\hat{\theta}_{m i}\right)$. Specifically, the order- $m$ efficiency score is derived from equation (4):

$$
\theta_{m}=E\left[\min _{i=1, \ldots, m}\left\{\max _{j=1, \ldots, p}\left(\frac{x_{i}^{j}}{x^{j}}\right)\right\} y_{i} \geq y\right]
$$

where the $\rho$-dimensional random variables $x_{i}, \ldots, x_{m}$ are drawn randomly and repeatedly from the conditional distribution of $\mathrm{X}$ given $y_{i} \geq y$. This estimator allows us to compare the efficiency of an observation with that of $m$ potential units that have a production larger or equal to $y$. As it does not include all the observations, it is less sensitive to outliers, extreme values or noise in the data. As $m$ increases, the expected order- $m$ estimator tends to the FDH efficiency score ( $\hat{\theta}_{F D H}$ ). For acceptable $m$ values, normally the efficiency scores will present values higher than unity, which indicates that students are inefficient, as outputs can be increased without modifying the level of inputs. When $\hat{\theta}<1$, the student can be labelled as super-efficient, since the order- $m$ frontier exhibits lower levels of outputs than the student under analysis. This is not possible in the traditional nonparametric framework where by construction $\hat{\theta} \geq 1$.

Moreover, this approach allows us to avoid the problem of bias that can arise when we compare groups of units on a different size, which is the case in our application with schools, since the mean level of efficiency generally depends on the existing observations in each school (Zhang and Bartels 1998). This problem can be reduced by using the same $m$ parameter for every school, which implies assuming that the performance of every student is compared to the same number of students independently of the number of students in his/her school. In our case, we determine the value of $m$ that equals the size of the smallest school in the data set (20), since it fits better in the metafrontier framework (see below). The main advantage of a lower trimming 
value $m$ is the reduced sensibility to outlying observations in the sample, although it also implies that the probability of drawing the evaluated observation is rather low and, consequently, we will observe more super-efficient observations.

\section{3. The metafrontier approach}

Independently of the method employed to estimate the efficiency coefficients, we need to bear in mind that part of those estimates derives from the environmental situation of the school they attend. Therefore, results obtained with frontier models need to control for this heterogeneity in order to give significance to the results.

For that purpose, we adapt the metafrontier approach developed by Battese and Rao (2002), Battese et al. (2004) and O'Donnell et al. (2008) to deal with a hierarchical structure in data, which is typical in the educational context, where students (level 1) are nested within schools (level 2). This approach measures the efficiency of units relative to separate best practice frontiers and allows us to decompose the performance of each student into a part attributable to the school and a part attributable to his/her skills. If there are $K$ schools, each having their own technology and environmental factors, a metafrontier is defined as the boundary of the unrestricted technology set. Hence, the metafrontier envelops each of the local group frontiers. Separately, the local efficiency of the student with regards to the type of school he is involved in is measured relative to the $n_{k}$ observations in the school sample:

$$
\theta^{k}\left(x_{k}, y_{k}\right)=\inf \left\{\theta^{k} \mid\left(\theta^{k} x_{k}, y_{k}\right) \in \psi^{k}\right\}
$$

where the technology set for group $k$ is defined as

$$
\psi^{k}=\left\{\left(x_{k}, y_{k}\right) \in \mathfrak{R}_{+}^{p+q} \mid x_{k} \text { can produce } y_{k}\right\}
$$

If all the schools have potential access to the same environment, all the observations can be pooled and students can be evaluated relative to the same standards. Thus, the metafrontier can be represented by the technology set defined by:

$$
\psi=\left\{(x, y) \in \mathfrak{R}_{+}^{p+q} \mid x \text { can produce } y\right\}
$$

This approach is basically an extension of the proposal by Silva Portela and Thanassoulis (2001) and Thanassoulis and Silva Portela (2002) to decompose the effect of school from 
students' inefficiency as well as to distinguish between the types of funding regime under which the school operates. Given the purpose of this paper, we are more interested in the latter issue, although we will take into account both aspects in the metafrontier framework. Thus, in a first step two different types of frontiers are defined: the local frontier specific for each school, which can be interpreted as the student-within-school efficiency and the overall frontier, which represents the student-within-all-schools efficiency. According to this definition, the distance to the local frontier depends only on the student's efficiency (STE) whereas the distance separating the local and the overall frontier can be interpreted as the school efficiency (SCE). This can be illustrated in Figure 1, where the efficiency level of a student $c$ depends on the level of the output achieved $\left(y_{c}\right)$ using his input endowment $\left(x_{c}\right)$. This student is inefficient, since there are students in the same school obtaining better results $(y)$ with the same amount of inputs $\left(x_{c}\right)$. The student effect can be defined by the ratio between the local potential output divided by the actual output $\left(S T E=\alpha^{\prime}=y^{\prime} / y_{c}\right)$. When this student is compared with the metafrontier, the overall efficiency can be defined as $O E=\alpha^{\prime \prime}=y^{\prime \prime} / y_{c}$. From those two measures of efficiency, the school effect can be automatically derived as $S C E=y^{\prime \prime} / y^{\prime}=O E / S T E$. In summary, the global efficiency can be decomposed in two effects: $O E=S T E x S C E$ (model 1) (Thanassoulis and Silva Portela 2002).

\section{(Figure 1 around here)}

However, in order to represent adequately the heterogeneity that exists in each school, the metafrontier needs to consider not only student data, but also additional variables representing the characteristics of schools and students attending the same school (Thieme et al. 2013). If we do not consider these variables, we are implicitly assuming that all the schools are operating with the most favourable environment, which would not be real in many cases. Therefore, it is possible to improve the definition of the school effect by considering additional variables. In particular, we incorporate information about some of the most frequently selected inputs for educational processes such as the socioeconomic status of students enrolled in the same school, i.e., the so-called peer effect, the teaching staff and the quality of educational resources (Ruggiero 2004). In addition, as we are interested in the identification of differences between public and private schools, we also include two additional variables with which we intend to capture the heterogeneity between the two types of schools: the percentage of native students and the degree of autonomy to decide about the selection of teachers and the allocation of resources. 
The consideration of the peer effect variable is based on the assumption that the composition of schools and classrooms is not random, since it typically reflects neighbourhood characteristics and therefore the family background of students. The existing literature has used a wide variety of approaches to identify the peer effect (Mc Ewan 2003; Lefgren 2004; Lavy et al. 2012), which is usually identified by some variable related to student's classmates. However, we construct a variable based on the average of the schoolmates' socioeconomic characteristics due to the lack of data at class level in the PISA dataset. The other school inputs (number of teachers and quality of educational resources) have also been considered as inputs in different studies focused on measuring efficiency using PISA data (e.g. Wilson 2005; Perelman and Santín 2011), since they are good proxies for human and capital resources managed by schools. Likewise, the consideration of the percentage of native pupils is based on the premise that in Spain those students are segregated among schools and mostly concentrated in public centres

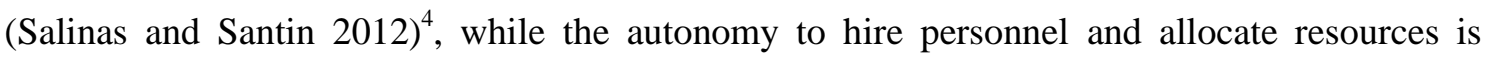
widely larger in private centres (Crespo et al. 2014). In particular, principals in public schools have no capacity to decide which profile of teachers should be hired (civil servants have stable position), while in state-subsidized private schools principals can manage the process to hire new teachers and configure a more homogeneous and focused staff what, finally, can improve the school's performance ${ }^{5}$.

However, there will also be a residual part of inefficiency detected in students' performance that cannot be explained by those five factors. In this sense, the estimation of a new model (model 2) allows us to expand the decomposition of the overall efficiency into two different school effects: $O E=S T E \times R S C E \times S C E$, where the school effect (SCE) can be attributed to the effect of those five variables included in the model, which can be defined as $S C E=\alpha_{1}=y^{\prime \prime} / y_{1}$, and the part attributed to other school factors can be identified as a residual school effect (RSCE). This decomposition is represented in Figure 2, where the metafrontier 2 considers the characteristics of students corresponding to the school under analysis, while metafrontier 1 assumes that the school has the optimal level of all these factors.

\section{(Figure 2 around here)}

The final step of our analysis consists of exploring whether the institutional form of the school interferes on the levels of efficiency, i.e, if there are still differences in the performance of

\footnotetext{
${ }^{4}$ This variable has also been considered in previous efficiency analyses in the Spanish context focused on the comparison between public and private schools (e.g. Mancebon et al. 2012).

${ }^{5}$ Nevertheless, public schools traditionally have more qualified teachers with better pedagogical skills and more experience. In addition, the long term horizon in public schools can influence a positive compromise of the teachers with the strategic goals of the school (López-Torres and Prior 2013).
} 
students according to the regime under which the school is operating. This can be tested simply by estimating a simple regression including a dummy to distinguish between public and private schools (Summers and Wolfe 1977; Toma and Zimmer 2000). However, in order to maintain the nonparametric structure of our model, we test this hypothesis by applying the method developed by Charnes et al. (1981) and extended by Silva Portela and Thanassoulis (2001), which implies a new decomposition of the metafrontier. In this case we do not incorporate any additional variable, but we only divide the whole sample of schools into two different subsamples, thus each student is only compared with others attending the same type of school (public or private). Therefore, the residual school effect (RSCE) is again decomposed into two different effects: the type of school $\left(S C T=\alpha_{2}=y_{1} / y_{2}\right)$ and the new residual school effect (RSCE $=y_{2} / y^{\prime} \geq 1$ ) (Figure 3). Once we have defined these new components of the overall inefficiency, it is straightforward to decompose it between the student effect, the type of school effect, the school effect attributable to the variables considered in the analysis and the residual school effect: $O E=S T E \times R S C E \times S C T \times S C E$ (model 3).

\section{(Figure 3 around here)}

\section{DATA AND VARIABLES}

In this study we assess the performance of Spanish students in PISA (Program for International Student Assessment) data set in 2009. This sample comprises more than 25,000 students who are enrolled in almost 900 schools, among which we can distinguish three different typologies: public, state-subsidized private and pure private schools. As we are only interested in comparing the performance of schools with a public funding, we excluded totally private schools from the sample $^{6}$, which only represented $3.4 \%$ of the original dataset. Likewise, we also removed schools were the number of available observations did not reach a minimum number of students (20) to avoid potential bias in the estimation of efficiency scores in local frontiers where the number of observations is lower than $m$. The selection of $m=20$ was based on the minimal level required to vary the proportion of super-efficient observations following the recommendation made by Daraio and Simar (2007). Likewise, it is worth noting that with this value the loss of information was not too relevant, since there were less than $10 \%$ of units below that value. As a result, our sample consists of 22,317 students belonging to 737 schools, among which two thirds are public and one third are state-subsidized schools (33\%). Table 1 provides information on both students and schools included in the sample.

\section{(Table 1 around here)}

\footnotetext{
${ }^{6}$ Following the same criterion used in Crespo-Cebada et al. (2014), private schools are classified as statesubsidized schools if they receive more than $50 \%$ of their funding from public authorities.
} 
With regard to the selection of variables, we follow the same approach used in Mancebon and Muñiz (2008), where a restrictive efficiency notion is estimated taking into account the relationship between the academic results obtained by students and their socio-economic background, since this indicator fulfils the requirements of being continuous and have high positive correlation with outcome variables (e.g. Coleman et al. 1966; Goldhaber and Brewer 1997; Hanushek 2003). According to this criterion, we evaluate whether the student is making the most of their potential ability, using his/her socioeconomic background as a proxy for this concept, or his/her performance is below the expected level, i.e., the student-within-school inefficiency.

The results obtained by students in the three competences evaluated in PISA, mathematics, reading comprehension and sciences are used as output indicators. These results are not expressed by only one value, but by five denominated plausible values randomly obtained from the distribution function of test results derived from the answers in each test (Rasch 1960, 1980), which can be interpreted as the representation of the ability range for each student (Mislevy et al. 1992; Wu and Adams 2002). Although PISA analysts recommend to use all of them to obtain more consistent estimations, in our analysis we use the mean value of those five plausible values, since the robustness of results is guaranteed by the use of the order- $m$ approach, which reduces the impact of measurement error by drawing repeatedly (B times) observations from the sample.

The input at student level is measured by students' socioeconomic background (ESCS), an index of economic, social and cultural status of students created by PISA analysts that captures a range of aspects of a student's family and home background that combines information on parents' education and occupations and home possessions. The first variable is the higher educational level of any of the student's parents according to the International Standard Classification of Education (ISCED, OECD, 1999). The second variable is the highest labour occupation of any of the student's parents according to the International Socio-economic Index of Occupational Status (ISEI, Ganzeboom et al. 1992). The third variable is an index of educational possessions related to household economy. Given that this continuous indicator presented negative values ${ }^{7}$, the original values have been rescaled by adding the maximum negative value to all of them, thus all the new quantities are positive. As a result, the variable fulfils the requirement of isotonicity (i.e., ceteris paribus, more input implies equal or higher level of output) preserving the desirable property of translation invariance (Cooper et al. 2007).

\footnotetext{
${ }^{7}$ The values of the PISA index of economic, social and cultural status were standardized to a mean of zero for the total population of students in OECD countries, with each country given equal weight.
} 
Additionally, we have selected five variables at school level to include information about the characteristics of schools where students are attending. The first variable is represented by schoolmates' background, i.e., the so-called peer-group effect (Patrinos 1995). It is defined as the average level in the variable ESCS of students from the same school, whose theoretical ground lies in the fact that the level of knowledge that can be achieved by a student depends directly on the characteristics of his/her schoolmates. The second variable is the number of teachers per 100 students (TEACHERS). This indicator was obtained as the ratio between the number of full-time teachers plus one-half times the number of part time teachers in each school and the total number of students enrolled in the school multiplied by 100. The third variable is an index representing the quality of school educational resources (SCMATEDU) derived from seven items measuring school principals' perceptions of potential factors hindering instruction at their school ${ }^{8}$. As all items were inverted for scaling, higher values on this index indicate better quality of educational resources. The forth variable is the percentage of native students in the school (PERCTNAT). Actually, we were interested in considering the proportion of immigrants, but we opted for the alternative of including the native ones to ensure a positive correlation with the output. Finally, we also include in the model an index representing the relative level of responsibility of school staff in allocating resources (RESPRES). This index is also created by PISA analysts according to the responses provided by principals on six questions about who has considerable responsibility for tasks regarding school management of selecting and firing teachers, establishing their starting salaries and increases and deciding about the school budget and allocations within the school. As well as the ESCS, this index was standardized to having an OECD mean of 0 and a standard deviation of 1 , with higher values on the scale indicating relatively higher levels of school responsibility in this area.

Table 2 reports a comparison between the values of public and private state-subsidized schools in the four selected variables at student level (three outputs and one input) as well as the five indicators at school level. We can observe that private schools obtain higher values in all the outcome variables. However those differences can be explained by the "higher quality" of pupils attending each type of school, represented by their socio economic index. Likewise, it is worth noting that public schools present a higher proportion of teachers than private schools while the differences in terms of educational resources are not significant. As expected, the percentage of native students is higher in private schools as well as the value of the responsibility index.

\footnotetext{
${ }^{8}$ These factors are: $i$ ) shortage or inadequacy of science laboratory equipment; $i$ ) shortage or inadequacy of instructional materials; iii) shortage or inadequacy of computers for instruction; $i v$ ) lack or inadequacy of Internet connectivity; v) shortage or inadequacy of computer software for instruction; $v i$ ) shortage or inadequacy of library materials; and vii) shortage or inadequacy of audio-visual resources.
} 
(Table 2 around here)

\section{RESULTS}

In this section we present the results obtained using the robust order- $m$ approach to estimate the efficiency levels $\left(\hat{\theta}_{m i}\right)$ in the three models. First, we estimate model 1, which only allows us to separate the school effect from overall efficiency calculated for each student. Secondly, we estimate two different metafrontiers in order to isolate the school effect from other components of inefficiency. Thus, model 2 determines the importance of several school factors and, subsequently, in model 3 we consider the different institutional rules affecting public and private schools. Therefore, in model 3 the school effect will appear as a residual, after isolating the impact of multiple school factors and institutional effects.

In our analysis, we use an output orientation, since both the individual students and the schools are attempting to maximize their attainment. As we mentioned previously, we select the value 20 for the $m$ parameter and we use 200 bootstrap iterations (B) for statistical inference. In the estimation of metafrontiers 1 and 2 we use the whole sample, while the estimation of metafrontier 3 requires the division of the sample between public and state subsidized private schools. Finally, the decomposition of inefficiency between different effects (student, school and type of school) requires the estimation of one partial frontier for each of the 737 evaluated schools.

Table 3 reports the summary statistics of the estimated scores for model 1 in all the schools. The overall efficiency $\left(\alpha^{\prime \prime}\right)$ for each student in the sample has a mean value of 1.1793 , which indicates that if all students would perform as efficiently as the best practice students, the test scores could increase on average by $18 \%$. It must be pointed out that, according to model 1 , most of the inefficiency found is attributable to the student effect (1.1279 on average), substantially higher than the school effect (1.0461 on average). Moreover, it is worth noting that some pupils have a performance score below 1. These super-efficient students are performing better than the average of the $(m=20)$ students they are benchmarked with. According to the data shown in Table 4, we can observe that there are significant divergences between public (1.2017) and private centres (1.1350). The level of inefficiency attributable to the student is similar in both types of centres, which means that most part of the differences on the overall inefficiency depends on the school effect. According to the structure of model 1, the effect attributable to the schools is obtained by dividing the overall efficiency score ( $\alpha$ ") by the student effect $\left(\alpha^{\prime}\right)$. Table 3 indicates that the mean value of this effect is $4.6 \%$, although behind these

\footnotetext{
${ }^{9}$ This percentage would be higher $(22.5 \%)$ if we only consider the inefficient students.
} 
values it is possible to detect that public schools are more inefficient than private schools (5.87\% vs. $2.11 \%$ in Table 4). Those differences are significant according to the value of the Mann-Whitney nonparametric test applied to these values.

(Table 3 around here)

(Table 4 around here)

Regarding this point, the results obtained for model 2 are especially informative, because they allow us to distinguish which part of the school inefficiency can be explained by the characteristics of the school students are attending. The results reported in Table 5 show that the importance of this factor is not too relevant if we consider the whole sample; however, the comparison between public and private schools (Table 6) alert us about the importance of this factor to explain the inefficiency of students attending public centres $(4.47 \%)$, since it represents around $76 \%$ of the initial average score attributed to the school effect $(5.87 \%)$. In contrast, this factor has a residual impact on private schools, since most of them are actually facing a favourable environment as we were assuming in model 1.

\section{(Table 5 around here)}

(Table 6 around here)

Finally, the values of the school type effect calculated in model 3 have a mean value very close to 1 , with a very low standard deviation for the whole sample (Table 7). This evidence shows that, once we have taken into account the characteristics of schools, the average effect attributable to the type of school on inefficiency is almost inexistent (0.998). Therefore, the remaining divergences in terms of inefficiency depend on the residual factor, i.e., those variables representing the characteristics of schools that have not been included in the analysis (residual school effect).

Although the importance of the school type effect is low, the comparison between public and state subsidized private schools (Table 8) allows us to identify that the average score assigned to this effect is lower in private schools than in public schools, which indicates that the former outperform the latter, since their students are obtaining better results despite they have less human resources ${ }^{10}$. In order to test the robustness of this result, we have also estimated a simple regression model in which the efficiency score attributed to the school effect (SCE) in model 2

\footnotetext{
${ }^{10}$ This evidence is confirmed by the existence of significant differences (at $1 \%$ level) in the mean values attributed to the school effect between the two subsamples, according to the values of the Mann-Whitney test.
} 
is regressed on a dummy variable representing the type of school (1 represents public schools). The results shown in Table 9 confirm that differences between both types of school regimes are slight but significant in favour of private schools, since the level of inefficiency of public schools is 2.5 points higher.

(Table 7 around here)

(Table 8 around here)

\section{CONCLUDING REMARKS}

In this paper we assess the performance of Spanish students in PISA 2009 using data at student level with the aim of finding divergences between public and state subsidized private schools. Given the uncertain about the specification of the production technology in education, we employ a nonparametric approach. In particular, this study represents the first attempt to measure the efficiency of Spanish students in secondary schools by combining the use of the recently developed order- $m$ approach with the metafrontier approach. The former method allows us to estimate robust measures of efficiency, while the latter makes it possible to decompose the effect of students, schools and the effect attributed to the type of school (differences between public and private schools).

The main conclusion that can be drawn from our analysis is that state subsidized private schools are more efficient, although the estimated inefficiency attributable to students is similar in both public and private schools. Actually, the final decomposition of inefficiency allows us to detect that the effect attributable to the school type is almost inexistent, while school factors have a great impact on results, especially with regard to the amount of human resources employed by each type of school.

Likewise, we have also detected that a significant proportion of inefficiency in public schools depends on the characteristics of students enrolled in those schools. Those divergences can be explained because students are not randomly distributed between both types of schools, since students with a lower socioeconomic status are prone to be enrolled in public schools due to the higher costs that would entail to attend state subsidized schools ${ }^{11}$.

Although our main findings must be interpreted cautiously, since they are based on cross sectional data, they are mainly in the same line of other studies performed using Spanish data,

${ }^{11}$ Crespo-Cebada et al. (2014) point out that educational materials, extra-curricular activities, school bus and lunch are usually more expensive in private schools (around 30\% higher). Moreover, in most private schools, parents are required to pay a fee to improve school facilities or to offer some extra-curricular activities while this fee does not exist in public schools. 
but adopting a very different methodological approach (e.g. Crespo-Cebada et al., 2014). Therefore, maybe it is time to analyze in greater detail the management or innovation strategies implemented by subsidized private schools, since they seem to be more efficient than public centres. In this sense, the decentralized structure of the Spanish educational system implies that the proportion of public and private schools differs across regions, thus a potential future line of research could be to explore whether our results are robust when we analyze the performance of schools operating in different regions.

\section{References}

Altonji JG, Elder TE, Taber CR (2005) Selection on observed and unobserved variables: Assessing the effectiveness of catholic schools. J Polit Econ 113(1):151-184.

Anand P, Mizala A, Repetto A (2009) Using school scholarships to estimate the effect of private education on the academic achievement of low-income students in Chile. Econ Educ Rev 28(3):370-381.

Banker RD, Janakiraman S, Natarajan R (2004) Analysis of trends in technical and allocative efficiency: an application to Texas public school districts, Eur J Oper Res 154:477-491.

Battese G, Rao D (2002) Technology gap, efficiency, and a stochastic metafrontier function. Intern J Bus 1(2):87-93.

Battese G, Rao D, O'Donnell C (2004) A metafrontier production function for estimation of technical efficiencies and technology gaps for firms operating under different technologies. $\mathrm{J}$ Produc Anal 21(1):91-103.

Bessent AM, Bessent EW (1980) Determining the Comparative Efficiency of Schools Through Data Envelopment Analysis. Educ Admin Quart, 16(2): 57-75.

Bessent AM, Bessent EW, Kennington J, Reagan B (1982) An application of mathematical programming to assess productivity in the Houston independent school district, Manage Sci, 28: $1355-1367$.

Bifulco R, Ladd HF (2006) The Impacts of Charter Schools on Student Achievement: Evidence from North Carolina. Educ Financ Polic 1(1):50-90.

Burgess S, Briggs A (2010) School assignment, school choice and social mobility. Econ Educ Rev 29:639-649.

Calero J, Escardibul JO (2007) Evaluación de servicios educativos: el rendimiento en los centros públicos y privados medido en PISA-2003. Hacienda Publica Esp 183(4):33-66.

Cazals C, Florens J, Simar L (2002) Nonparametric frontier estimation: a robust approach. J Econom 106:1-25.

Charnes A, Cooper WW, Rhodes E (1978) Measuring the Efficiency of Decision Making Units. Eur J Oper Res 2(6):429-444.

Charnes A, Cooper WW, Rhodes E (1981) Evaluating Program and Managerial Efficiency: An application of Data Envelopment Analysis to Program Follow Through. Manag Sci 27:668-697. 
Cherchye L, De Witte K, Ooghe E, Nicaise I (2010) Efficiency and equity in private and public education: A nonparametric comparison. Eur J Oper Res 202:563-573.

Chubb JE, Moe TM (1990) Politics, markets and America's schools. The Brookings Institution, Washington.

Chudgar A, Quin E (2012) Relationship between private schooling and achievement: Results from rural and urban India. Econ Educ Rev 31(4):376-390.

Coleman J, Campbell E, Hobson C, McPartland J, Mood A, Weinfield F, York R (1966) Equality of Education Opportunity. Government Printing Office, Washington D.C.

Coleman J, Hoffer T, Kilgore S (1982) Secondary school achievement. Public, catholic and private schools compared. Basic Books Inc. Publishers, New York.

Cooper WW, Seiford L, Tone K (2007) Data Envelopment Analysis. A Comprehensive Text with Models, Applications, References and DEA-Solver Software. Springer, New York.

Crespo-Cebada E, Pedraja F, Santín D (2014) Does school ownership matter? An unbiased efficiency comparison for regions of Spain. J Produc Anal 41(1):153-172.

Daraio C, Simar L (2007) Advanced robust and nonparametric methods in efficiency analysis. Methodologies and Applications. Springer, New York.

Deprins D, Simar L, Tulkens H (1984) Measuring Labor Inefficiency in Post Offices. In: Marchand P, Pestieau P and Tulkens H (eds.). Concepts and Measurements. Amsterdam, North Holland, pp 243-267.

De Witte K, Kortelainen M (2013) What explains performance of students in a heterogeneous environment? Conditional efficiency estimation with continuous and discrete environmental variables. App Econ 45(17):2401-2412.

De Witte K, Thanassoulis E, Simpson G, Battisti G and Charlesworth-May A (2010) Assessing pupil and school performance by non-parametric and parametric techniques. J Oper Res Soc 61:224-1237.

Dronkers J, Avram S (2010) A cross-national analysis of the relations between school choice and effectiveness differences between private-dependent and public schools. Educ Res Eval 16 (2):1551-175.

Dronkers J, Robert P (2008) Differences in scholastic achievement of public, private government-dependent and private independent schools. A cross-national analysis. Educ Policy 22(4):541-577.

Friedman M, Friedman R (1981) Free to choose. Avon, New York.

Ganzeboom H, De Graaf P, Treiman J, De Leeuw J (1992) A standard internacional socioeconomic index of occupational status. Soc Sci Res 21(1):1-56.

Goldhaber DD (1996) Public and private secondary schools. Is school choice an answer to the productivity problem? Econ Educ Rev 15(2):93-109.

Goldhaber DD, Brewer DJ (1997) Why don't schools and teachers seem to matter? Assessing the impact of unobservables on educational productivity. J Hum Resour 32:505-523. 
Goldstein H (1997) Methods in school effectiveness research. Sch Eff Sch Improv, 8: 369-395.

Grosskopff S, Moutray C (2001) Evaluating performance in Chicago public high schools in the wake of decentralization, Econ Educ Rev 20(1):1-14.

Hanushek EA (1979) Conceptual and empirical issues in the estimation of educational production functions. J Hum Resour, 14 (3), 351-388.

Hanushek EA (1986) The economics of schooling: production and efficiency in public schools. J Econ Lit, 24, 1141-1177.

Hanushek EA (2003) The failure of input based schooling policies. Econ J 113:64-98.

Hanushek EA, Rivkin SG, Taylor LL (1996) Aggregation and the estimated effects of school resources. Rev Econ Stat 78(4):611-627.

Hoxby CM (2003) The economics of school choice. University of Chicago Press, Chicago. Hsieh CT, Urquiola M (2006) The effects of generalized school choice on achievement and stratification: Evidence from Chile's voucher program. J Pub Econ 90(8-9):1477-1503.

Jimenez E, Lockheed ME, Paqueo V (1991) The relative efficiency of private and public schools in developing countries. World Bank Res Obs 6:205-218.

Kim YJ (2011) Catholic schools or school quality? The effects of Catholic schools on labor market outcomes. Econ Educ Rev 30(3):546-558.

Kneip A, Park BU, Simar L (1998) A note on the convergence of nonparametric DEA estimators for production efficiency scores. Econom Theory 14(6):783-793.

Lavy V, Silva O, Weinhardt F (2012) The good, the bad and the average: evidence on ability peer effects in schools. J Labor Econ 30(2): 367-414.

Lefgren L (2004) Educational peer effects and the Chicago public schools. J Urban Econ $56: 169-191$.

López-Torres L, Prior D (2013) Do parents perceive the technical quality of public schools? an activity analysis approach. Reg Sect Econ Stud 13(3):39-60.

Mancebón MJ, Bandrés E (1999) Efficiency Evaluation in Secondary Schools: The key role of model specification and of ex post analysis of results, Educ Econ, 7(2):131-152.

Mancebón MJ, Calero J, Choi A, Ximénez-de-Embún D (2012) The efficiency of public and publicly subsidized high schools in Spain: Evidence from PISA-2006. J Oper Res Soc 63:15161533.

Mancebón MJ, Molinero CM (2000) Performance in primary schools. J Oper Res Soc 51:843854.

Mancebón MJ, Muñiz M (2008) Private versus public high schools in Spain: disentangling managerial and programme efficiencies. J Oper Res Soc 59:892-901.

Mayston DJ (2003) Measuring and managing educational performance. J Oper Res Soc 54:679691. 
McEwan PJ (2001) The Effectiveness of Public, Catholic, and Non-Religious Private Schools in Chile's Voucher System. Educ Econ 9(2):103-128.

McEwan PJ (2003) Peer effects on student achievement: Evidence from Chile. Econ Educ Rev 22(2):131-141.

McEwan PJ, Carnoy M (2000) The Effectiveness and Efficiency of Private Schools in Chile's Voucher System. Educ Eval Policy Anal 22(3):213-239.

Mislevy RJ, Beaton AE, Kaplan B, Sheehan KM (1992) Estimating population characteristics form sparse matrix samples of item responses. J Educ Meas 29:133-161.

Newhouse D, Beegle K (2006) The effect of school type on academic achievement. J Hum Res 41(3):529-557.

O'Donnell C, Rao D, Battese G (2008) Metafrontier frameworks for the study of firm-level efficiencies and technology ratios. Empir Econ 37(2):231-255.

Oliveira MA, Santos C (2005) Assessing school efficiency in Portugal using FDH and bootstrapping. Appl Econ 37(8):957-968.

Park B, Simar L, Weiner C (2000) The FDH estimator for productivity efficiency scores. Econ Theory 16(6): 855-877.

Patrinos HA (1995) Socioeconomic background, schooling, experience, ability and monetary rewards in Greece. Econ Educ Rev 14(1):85-91.

Perelman S, Santín D (2011) Measuring educational efficiency at student level with parametric stochastic distance functions: an application to Spanish PISA results. Educ Econ 19(1):29-49.

Rasch G (1960/1980) Probabilistic models for some intelligence and attainment tests. Danish Institute for Educational Research, Expanded edition (1980). The University of Chicago Press, Copenhagen.

Rouse C, Barrow L (2009) School vouchers and Student Achievement: Recent Evidence, Remaining Questions. Annu Rev Econ September:17-42.

Ruggiero J (2004) Performance evaluation in education. In Handbook on data envelopment analysis (pp. 323-346). Springer US.

Salinas J, Santin D (2012) School choice and the influence of immigration on Spanish educational achievements in PISA 2006, Rev Educ, 358:382-405.

Sander W (1996) Catholic grade schools and academic achievement. J Hum Res 31(3):540-548.

Santín D (2006) La medición de la eficiencia de las escuelas: una revisión crítica. Hacienda Publica Esp 177(2):57-83.

Silva Portela MC, Thanassoulis E (2001) Decomposing school and school-type efficiency. Eur J Oper Res 132(2):357-373.

Simar L, Wilson PW (2000) Statistical inference in nonparametric frontier models: The state of the art. J Prod Anal 13(1): 49-78.

Summers AA, Wolfe BL (1977) Do schools make a difference? Am Econ Rev 67(4): 639-652. 
Tamm M (2008) Does money buy higher schooling?: Evidence from secondary school track choice in Germany. Econ Educ Rev 27(5):536-545.

Thanassoulis E, Dunstan P (1994) Guiding schools to improved performance using data envelopment analysis: An illustration with data from a local education authority, J Oper Res Soc 45(11):1247-1262.

Thanassoulis E, Silva Portela MCA (2002) School Outcomes: Sharing the Responsibility Between Pupil and School. Educ Econ 10(2):183-207.

Thieme C, Prior D, Tortosa-Ausina E (2013) A multilevel decomposition of school performance using robust nonparametric frontier techniques. Econ Educ Rev 32:104-121.

Toma EF (1996) Public funding and private schooling across countries. J Law Econ 39(1):121148.

Toma EF, Zimmer RW (2000) Peer effects in private and public schools across countries. J Policy Anal Manag 19(1):75- 92.

Vandenberghe V, Robin S (2004) Evaluating the effectiveness of private education across countries: a comparison of methods. Lab Econ 11(4), 487-506.

Waldo S (2007) On the use of student data in efficiency analysis. Technical efficiency in Swedish upper secondary school, Econ Educ Rev, 26:173-185.

Williams T, Carpenter P (1991) Private schooling and public achievement in Australia. Int J Educ Res 5:411-431.

Wilson PW (2005) Efficiency in education production among PISA countries, with emphasis on transitioning economies, in World Bank Working Paper.

Wu M, Adams RJ (2002) Plausible Values - Why They Are Important. International Objective Measurement Workshop, New Orleans.

Zhang Y, Bartels R (1998) The effect of sample size on the mean efficiency in DEA with an application to electricity distribution in Australia, Sweden and New Zealand. J Prod Anal 9(3):187-204. 